\title{
Bagan Kendali Robust Multivariat untuk Pengamatan Individual
}

\author{
*Seltuti, Erna Tri Herdiani ${ }^{* 1}$, Nirwan Ilyas ${ }^{* 2}$
}

\begin{abstract}
The most widely used of control chart in multivariate control processing is control chart $\mathrm{T}^{2}$ Hotelling. There are 2 kinds of control chart $\mathrm{T}^{2}$ Hotelling, namely $\mathrm{T}^{2}$ Hotelling for group observation and $\mathrm{T}^{2}$ Hotelling for individual observation. In this paper, discuss the control chart $\mathrm{T}^{2}$ Hotelling for individual observation. This control chart is used for monitoring of mean vector and sample of covariance matrix. Mean vector and sample of covariance matrix are very sensitive with respect to extreme point (outliers). Therefore, it is needed an estimator of mean vector and has a stocky population covariance matrix to the outliers data. One method that can be used to detect data that contains outliers is Minimum Covariance Determinant (MCD). From the calculation results, obtained that control chart $\mathrm{T}^{2}$ Hotelling by using FastMCD algorithm is more sensitive to detect outliers data than $\mathrm{T}^{2}$ Hotelling classically.
\end{abstract}

Keyword: $\mathrm{T}^{2}$ Hotelling, Minimum Covariance Determinant (MCD), robust, outlier

\begin{abstract}
Abstrak
Bagan kendali yang paling banyak digunakan dalam pengendalian proses secara multivariat adalah bagan kendali $\mathrm{T}^{2}$ Hotelling. Ada 2 jenis dari bagan kendali $\mathrm{T}^{2}$ Hotelling yaitu bagan kendali $\mathrm{T}^{2}$ Hotelling untuk pengamatan kelompok dan individual. Pada tulisan ini membahas bagan kendali $\mathrm{T}^{2}$ Hotelling untuk pengamatan individual. Bagan kendali ini digunakan untuk memonitor vektor rata-rata dan matriks kovariansi sampel. Vektor rata-rata dan matriks kovariansi sampel sangat sensitif terhadap titik ekstrim (outliers). Oleh karena itu dibutuhkan estimator vektor rata-rata dan matriks kovariansi populasi yang kekar terhadap data outliers. Salah satu metode yang dapat digunakan untuk mendeteksi data yang mengandung outliers adalah Minimum Covariance Determinant (MCD). Dari hasil perhitungan diperoleh bahwa bagan kendali $\mathrm{T}^{2}$ Hotelling dengan algoritma Fast-MCD lebih sensitif mendeteksi data outliers daripada $\mathrm{T}^{2}$ Hotelling klasik.
\end{abstract}

Kata Kunci: $\mathrm{T}^{2}$ Hotelling, Minimum Covariance Determinant (MCD), robust, outlier.

\section{Pendahuluan}

Bagan kendali kualitas atau yang disebut control chart merupakan salah satu alat yang digunakan dalam usaha mengendalikan kualitas proses karena dalam bagan kendali dapat diketahui kapan proses berada di luar kendali (out of control). Untuk mengukur dua atau lebih karakteristik kualitas secara bersamaan digunakan bagan kendali multivariat yang diperkenalkan oleh Harold Hotelling. Bagan kendali ini dikenal sebagai bagan kendali $\mathrm{T}^{2}$ Hotelling. Menurut Montgomery (2009), bagan kendali $\mathrm{T}^{2}$ Hotelling paling banyak digunakan dalam pengendalian proses secara multivariat untuk memonitor vektor rata-rata proses karena dalam bagan kendali $\mathrm{T}^{2}$ Hotelling menggunakan vektor rata-rata dan matriks kovariansi dari sampel. Vektor rata-rata dan matriks kovariansi sampel sangat sensitif terhadap titik ekstrim (outliers). Karena itu dibutuhkan estimator vektor rata-rata dan matriks kovariansi populasi yang kekar terhadap data pencilan untuk membuat bagan kendali $\mathrm{T}^{2}$ Hotelling.

Salah satu metode yang cukup terkenal adalah Minimum Covariance Determinant (MCD)[9]. Menurut berbagai penelitian antara lain Rousseeuw dan van Driesen (1998), Hubert dan van Driessen "Program Studi Statistika, Departemen Matematika, FMIPA, Universitas Hasanuddin

${ }^{1}$ herdiani.erna@gmail.com, ${ }^{2}$ nirwanilyas@yahoo.com 
Seltuti, Erna Tri Herdiani, Nirwan Ilyas

(2002), penaksir robust dengan metode MCD dapat memberikan angka ketepatan yang lebih baik dibanding metode-metode yang lainnya. Namun, pada metode MCD, apabila data berdimensi cukup besar, akan sulit dilakukan karena terdapat banyak kombinasi sub sampel yang harus ditemukan oleh penaksir MCD. Oleh karena itu, Roussew dan Van Driessen (1999) menemukan algoritma FastMCD. Dari sudut pandang ketersediaan paket program, MCD telah terakomodir dalam S-PLUS, Matlab dan SAS dengan menggunakan algoritma Fast-MCD. Penaksir Fast-MCD merupakan estimasi dengan menggunakan rata-rata dan kovariansi dari sebagian pengamatan yang meminimumkan determinan matriks kovariansi. Metode Fast-MCD selain memenuhi sifat statistik high breakdown point (dapat mengatasi pencilan sampai 50\%), juga efisien dalam komputasinya dan yang paling penting adalah efektif dalam mengatasi pengamatan yang mengandung pencilan. Berdasarkan hal tersebut, dalam penulisan tugas akhir ini membahas bagan kendali robust multivariat untuk pengamatan individual diterapkan untuk menentukan pengamatan yang out of control dari bahan Clay Putih sebagai bahan pengisi dan pengikat untuk pupuk NPK Phonska.

\section{Tinjuan Pustaka}

\subsection{Pengendalian Kualitas}

Pengendalian proses multivariat merupakan salah satu bagian dari pengendalian kualitas yang cepat berkembang karena ada banyak situasi real yang melibatkan lebih dari dua karakteristik kualitas proses yang saling berhubungan. Pengendalian proses multivariat ini selanjutnya dikenal sebagai Multivariate Statistic Proses Control (Erna, 2014). Seperti halnya SPC, dalam MSPC juga terdapat bagan kendali. Bagan kendali multivariat digunakan untuk memantau peubah secara bersama-sama pada suatu proses. Proses yang dilakukan dikatakan terkendali jika tidak ada pengamatan yang berada di luar batas kendali (outlier).

\subsection{Analisis Multivariat}

Analisis multivariat merupakan analisis yang melibatkan banyak variabel (lebih dari dua). Asumsi-asumsi pada analisis multivariat adalah variabel karakteristik harus saling berkorelasi dan berdistribusi normal multivariat [7].

\subsubsection{Uji Korelasi}

Korelasi adalah suatu ukuran yang menyatakan kekuatan hubungan antara 2 variabel [9]. Perhitungan koefisien korelasi Pearson antara variabel $X_{j}$ dan $X_{k}$, yaitu :

$$
\begin{gathered}
\boldsymbol{\rho}_{X_{j} X_{k}}=\frac{\operatorname{cov}\left(X_{j}, X_{k}\right)}{\sqrt{\operatorname{var}\left(X_{j}, X_{j}\right)} \sqrt{\operatorname{var}\left(X_{k}, X_{k}\right)}} \\
=\frac{\sum_{i=1}^{N}\left(X_{i j}-\bar{X}_{j}\right)\left(X_{i k}-\bar{X}_{k}\right)}{\sqrt{\sum_{i=1}^{N}\left(X_{i j}-\bar{X}_{j}\right)^{2}} \sqrt{\sum_{i=1}^{N}\left(X_{i k}-\bar{X}_{k}\right)^{2}}}
\end{gathered}
$$

Berikut merupakan uji korelasi.

1. Hipotesis :

$H_{0}: \boldsymbol{\rho}=\mathbf{I}$ (tidak terdapat korelasi antar variabel).

$H_{1}: \boldsymbol{\rho} \neq \mathbf{I}$ (terdapat korelasi antar variabel).

2. Statistik uji :

$$
T=\frac{(n-1)}{(1-r)^{2}}\left[\sum \sum_{j<k}\left(r_{j k}-\bar{r}\right)^{2}-\hat{\gamma} \sum_{k=1}^{p}\left(\bar{r}_{k}-\bar{r}\right)^{2}\right]
$$

dengan :

$r_{j k}=r_{X_{j} X_{k}}$ 


$$
\begin{aligned}
\bar{r}_{k} & =\frac{1}{p-1} \sum_{\substack{j=1 \\
j \neq k}}^{p} r_{j k} ; k=1,2, \ldots, p \\
\bar{r} & =\frac{2}{p(p-1)} \sum \sum_{j<k} r_{j k} \\
\hat{\gamma} & =\frac{(p-1)^{2}\left[1-(1-\bar{r})^{2}\right]}{p-(p-2)(1-\bar{r})^{2}}
\end{aligned}
$$

\section{Kriteria Pengujian :}

Jika statistik uji $T>\chi_{\frac{(p+1)(p-2)}{2},(\alpha)}^{2}$, maka $H_{0}$ ditolak. Sehingga dapat disimpulkan $H_{1}$ diterima bahwa terdapat korelasi yang signifikan antar variabel.

\subsubsection{Distribusi Normal Multivariat}

Pada bagan kendali multivariat, pengujian distribusi normal multivariat dilakukan untuk menguji apakah distribusi data yang akan dianalisis telah berdistribusi normal multivariat sebagai asumsi dasar yang harus dipenuhi dalam analisis multivariat [7].

Berikut pengujian distribusi normal multivariat:

1. Hipotesis :

$H_{0}=$ data berdistribusi normal multivariat.

$H_{1}=$ data tidak berdistribusi normal multivariat.

2. Statistik Uji :

$$
\begin{aligned}
& d_{i}^{2}=\left(\boldsymbol{X}_{\boldsymbol{i} \boldsymbol{j}}-\overline{\boldsymbol{X}}_{\boldsymbol{j}}\right)^{T} \boldsymbol{S}^{-\mathbf{1}}\left(\boldsymbol{X}_{\boldsymbol{i} \boldsymbol{j}}-\overline{\boldsymbol{X}}_{\boldsymbol{j}}\right) ; \\
& i=1,2, \ldots, n ; j=1,2, \ldots, p
\end{aligned}
$$

3. Kriteria pengujian

Data dapat dikatakan berdistribusi normal multivariat atau dapat dikatakan gagal menolak $H_{0}$ apabila terdapat minimal $50 \%$ nilai $d_{i}^{2} \leq \chi_{(p ; 0,5)}^{2}$ atau hasil dari scatter plot berupa garis lurus [7].

\subsection{Estimator Robust Minimum Covariance Determinant (MCD)}

Menurut Hubert dkk (2005) penaksir robust Minimum Covariance Determinant (MCD) merupakan rata-rata kovariansi dari sebagian pengamatan yang meminimumkan determinan matriks kovariansi. Misalkan vektor random $\boldsymbol{X}=\left[X_{1}, X_{2}, \ldots, X_{p}\right]^{\prime}$ merupakan himpunan data sejumlah $n$ pengamatan yang terdiri dari $p$ variabel, dimana $n \geq p+1$. Penaksir MCD merupakan pasangan ratarata sub sampel $\overline{\boldsymbol{x}}$ dan $\mathbf{S}$ yang merupakan matriks definit positif simetri berdimensi $p \times p$ dari suatu sub sampel berukuran $h$ pengamatan dimana $\frac{n+p+1}{2} \leq h \leq n$ dengan

$$
\begin{aligned}
& \overline{\boldsymbol{x}}=\frac{1}{h} \sum_{i=1}^{h} x_{i}=\frac{x_{1}+x_{2}+\cdots+x_{h}}{h} \\
& \boldsymbol{S}=\frac{1}{h-1} \sum_{i=1}^{h}\left(x_{i}-\overline{\boldsymbol{x}}\right)\left(x_{i}-\overline{\boldsymbol{x}}\right)^{\prime}
\end{aligned}
$$

Algoritma yang terkenal dalam menaksir estimator MCD adalah Fast-MCD yang diusulkan oleh Rousseuw dan van Driessen (1999).

Algortima Fast-MCD dapat dilakukan dengan langkah-langkah sebagai berikut:

1. Ambil sejumlah $h$ pengamatan yang berbeda secara acak. Dari $n$ pengamatan akan dihasilkan $\left(\begin{array}{l}n \\ h\end{array}\right)$ himpunan yang baru. Nilai $h$ yang optimal memenuhi $(n+p+1) / 2$. 
2. Definisikan himpunan pertama sebagai $H_{1}$. Berdasarkan himpunan $H_{1}$ hitung vektor rata-rata dan matriks kovariansi $\left(\overline{\boldsymbol{x}}_{1}, \boldsymbol{S}_{1}\right)$ menggunakan rumus pada persamaan (3) dan (4).

3. Menghitung jarak mahalanobis dengan menggunakan rumus:

$$
d_{1}(i)=\sqrt{\left(x_{i}-\overline{\boldsymbol{x}}_{1}\right)^{\prime} \boldsymbol{S}_{1}^{-1}\left(x_{i}-\overline{\boldsymbol{x}}_{1}\right)}
$$

4. Mengurutkan $d_{1}(i)$ dari nilai terkecil ke nilai yang terbesar.

5. Definisikan himpunan bagian baru dengan $H_{2}$, sedemikian sehingga $\left\{d_{1}(i) ; i \in H_{2}\right\}:=$ $\left\{\left(d_{1}\right)_{1: n,}\left(d_{1}\right)_{2: n}, \cdots,\left(d_{1}\right)_{h: n}\right\}$, dimana $\left(d_{1}\right)_{1: n} \leq\left(d_{1}\right)_{2: n} \leq \cdots\left(d_{1}\right)_{h: n}$.

6. Menghitung vektor rata-rata dan matriks kovariansi $\left(\overline{\boldsymbol{x}}_{2}, \boldsymbol{S}_{2}\right)$ dari $H_{2}$

7. Bandingkan $\operatorname{det}\left(\boldsymbol{S}_{2}\right)$ dengan $\operatorname{det}\left(\boldsymbol{S}_{1}\right)$. Bila $\operatorname{det}\left(\boldsymbol{S}_{2}\right)>\operatorname{det}\left(\boldsymbol{S}_{1}\right)$ ulangi langkah pada poin (1) sampai (6) hingga ditemukan bahwa $\operatorname{det}\left(\boldsymbol{S}_{m+1}\right) \leq \operatorname{det}\left(\boldsymbol{S}_{m}\right)$.

\subsection{Bagan Kendali $\mathrm{T}^{2}$ Hotelling}

Bagan kendali $\mathrm{T}^{2}$ Hotelling digunakan untuk mendeteksi pergeseran proses dengan menggunakan vektor mean sampel dan matriks kovariansi sampel. Nilai $\mathrm{T}^{2}$ untuk masing-masing sampel adalah

$$
\mathrm{T}_{\mathrm{i}}^{2}=\mathrm{n}\left(\overline{\mathbf{X}}_{\mathrm{ij}}-\overline{\overline{\mathbf{X}}}\right) \mathbf{S}^{-1}\left(\overline{\mathbf{X}}_{\mathrm{ij}}-\overline{\overline{\mathbf{X}}}\right)
$$

dengan $n$ adalah ukuran masing-masing sampel dan $\mathbf{S}^{-1}$ merupakan invers dari matriks kovariansi $S$ sedangkan batas pengendali atas (BPA) dapat ditentukan dari persamaan berikut :

$$
\mathrm{BPA}=\left(\frac{\mathrm{mnp}-\mathrm{mp}-\mathrm{np}+\mathrm{p}}{\mathrm{mn}-\mathrm{m}-\mathrm{p}+1}\right) \mathrm{F}_{\alpha, \mathrm{p},(\mathrm{mn}-\mathrm{m}-\mathrm{p}+1)}
$$

dengan $m$ menyatakan banyaknya sampel yang masing - masing berukuran $n$. Jika nilai $\mathrm{T}_{\mathrm{i}}^{2}$ untuk sampel ke-i, $\mathrm{T}_{\mathrm{i}}^{2}>$ BPA maka hal ini menunjukkan bahwa sampel ke -i di luar kendali.

Jika pada saat proses pengamatan tidak terdapat subgrup atau data bersifat individu maka digunakan bagan kendali $\mathrm{T}^{2}$ Hotelling individu. Berikut perhitungan peta kendali $\mathrm{T}^{2}$-Hotelling individu (Montgomery,2009).

$$
\mathrm{T}_{\mathrm{i}}^{2}=\left(\mathbf{X}_{\mathbf{i j}}-\overline{\mathbf{X}}_{\mathbf{j}}\right)^{\mathrm{T}} \mathbf{S}^{-1}\left(\mathbf{X}_{\mathbf{i j}}-\overline{\mathbf{X}}_{\mathbf{j}}\right) \quad \mathrm{i}=1,2, \ldots, \mathrm{n} 1,2, \ldots, \mathrm{p}
$$

Batas kendali $\mathrm{T}^{2}$ Hotelling untuk pengamatan individual dengan $\mathrm{m}$ sampel, dapat dirumuskan dengan persamaan (2.13).s

$$
\begin{aligned}
& \mathrm{BPA}=\frac{(\mathrm{m}-1)^{2}}{\mathrm{~m}} \beta_{\alpha, \frac{\mathrm{p}}{2}(\mathrm{~m}-\mathrm{p}-1) / 2} \\
& \mathrm{BPB}=0
\end{aligned}
$$

\subsection{Indeks Kemampuan Proses}

Analisis Kapabilitas proses adalah suatu analisis yang digunakan untuk menaksir kemampuan proses. Analisis kapabilitas proses dapat digunakan setelah proses produksi telah terkendali secara statistik. Berikut merupakan kriteria nilai kapabilitas [2].

1. $C p=1$, Kemampuan proses sesuai

2. $C p>1$, Kemampuan proses sangat baik (tingkat presisi dan akurasi tinggi)

3. $C p<1$, Kemampuan proses tidak baik

Rumus Indeks Kemampuan Proses $(C p)$ multivariat :

$$
(C p)=\frac{K}{\chi_{p, 0,95}^{2}}\left(\frac{(n-1) p}{s}\right)^{\frac{1}{2}}
$$

dengan : 


$$
\begin{gathered}
s=\sum_{i=1}^{n}\left(\boldsymbol{X}_{i}-\overline{\boldsymbol{X}}_{j}\right) \boldsymbol{A}^{-\mathbf{1}}\left(\boldsymbol{X}_{i}-\overline{\boldsymbol{X}}_{j}\right) \\
\boldsymbol{A}^{-\mathbf{1}}=\boldsymbol{X}_{i}{ }^{\prime} \boldsymbol{X}_{i} \\
K=\sqrt{\left(\overline{\boldsymbol{X}}_{j}-\boldsymbol{\varepsilon}_{j}\right)^{\prime} \boldsymbol{V}_{\mathbf{0}}^{-\mathbf{1}}\left(\overline{\boldsymbol{X}}_{j}-\boldsymbol{\varepsilon}_{j}\right)} \\
i=1,2,3, \ldots, n ; j=1,2,3 \\
\boldsymbol{\varepsilon}_{j}=\frac{1}{2}(B S A+B S B)
\end{gathered}
$$

\section{Metode Analisis}

Langkah-langkah yang dilakukan berdasarkan tujuan penelitian adalah sebagai berikut :

1. Pengambilan data sekunder PT Petrokimia Gresik berupa data parameter kualitas Clay Putih sebagai material balance atau bahan pengisi dan pengikat dalam proses produksi pupuk NPK Phonska, yaitu $\mathrm{H}_{2} \mathrm{O}$, Mesh, dan Derajat Putih.

2. Menguji korelasi untuk mengetahui hubungan antar variabel.

3. Melakukan uji distribusi normal multivariat agar asumsi dasar yang harus dipenuhi dalam analisis multivariat terpenuhi.

4. Mengestimasi vektor rata-rata dan matriks kovariansi berdasarkan algoritma fast-MCD.

5. Menghitung bagan kendali $\mathrm{T}^{2}$ Hotelling klasik dan $\mathrm{T}^{2}$ Hotelling dengan algoritma fast-MCD.

6. Membandingkan nilai $\mathrm{T}^{2}$ setiap pengamatan dengan BPA. Jika $\mathrm{T}_{\mathrm{i}}^{2} \leq B P A$ maka data pengamatan ke-i berada pada batas kendali (in control). Sebaliknya jika $\mathrm{T}_{\mathrm{i}}^{2}>B P A$, maka data pengamatan ke- $i$ berada di luar kendali (out of control).

7. Menentukan kapabilitas proses dari bagan kendali $\mathrm{T}^{2}$ Hotelling dengan menggunakan data Clay Putih sebagai material balance dalam proses produksi pupuk NPK Phonska.

8. Menarik kesimpulan dari hasil penelitian.

\section{Hasil dan Pembahasan}

Pada penelitian ini, analisis vektor rata-rata dan matriks kovarian pada bagan kendali $\mathrm{T}^{2}$ Hotelling dengan algoritma Fast-MCD akan dilakukan pada data sekunder produksi pupuk bahan Clay Putih.

Hasil perhitungan $\mathrm{T}^{2}$ Hotelling menunjukkan bahwa terdapat 14 pengamatan yang out of control untuk data produksi pupuk bahan Clay Putih.

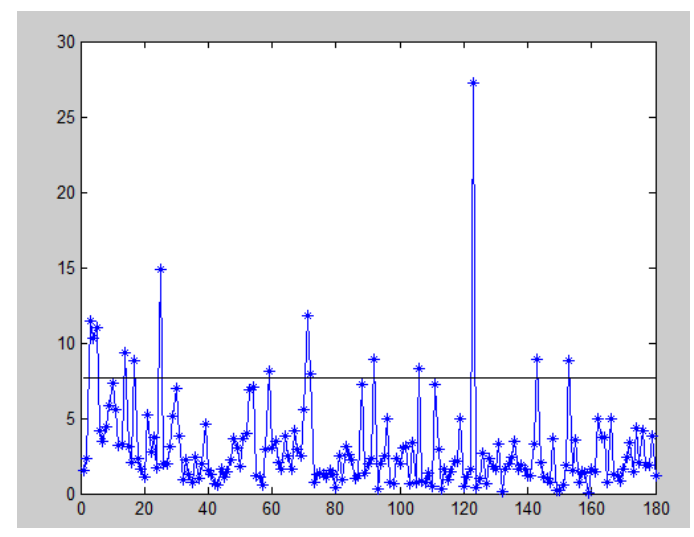


Seltuti, Erna Tri Herdiani, Nirwan Ilyas

Gambar 1. bagan kendali $\mathrm{T}^{2}$ Hotelling dengan pengamatan yang out of control

Untuk mencapai proses in control, data yang out of control perlu dihilangkan. Gambar 2. pada bagan kendali $\mathrm{T}^{2}$ Hotelling menunjukkan bahwa untuk mencapai proses in control perlu di lakukan 9 kali iterasi penghapusan data out of control.

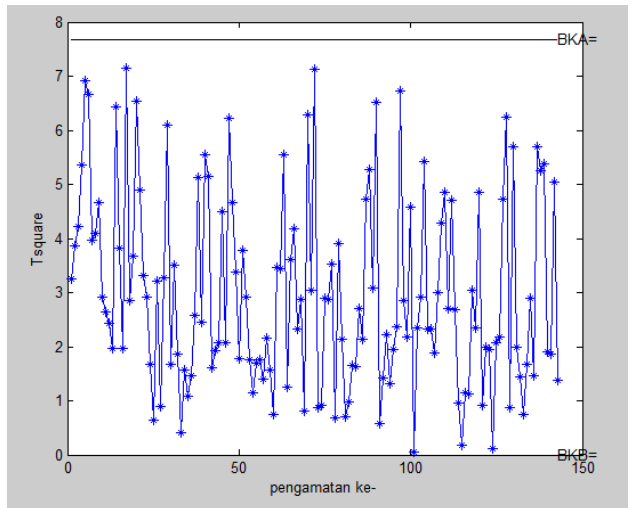

Gambar 2. bagan kendali $\mathrm{T}^{2}$ Hotelling dengan pengamatan in control

Selanjutnya bagan kendali $\mathrm{T}^{2}$ Hotelling dengan algoritma Fast-MCD dapat kita lihat pada Gambar 3.

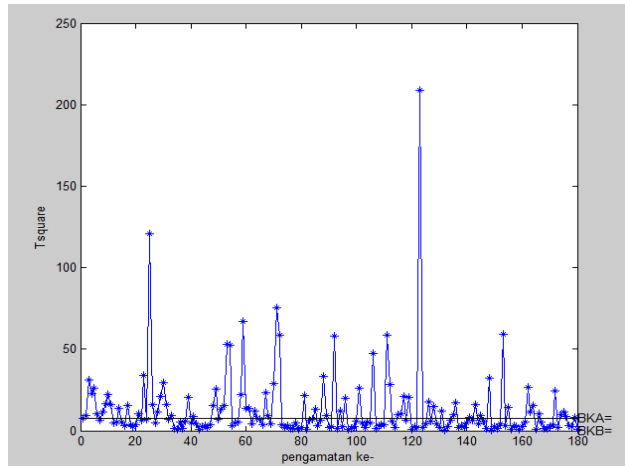

Gambar 3. Bagan kendali $\mathrm{T}^{2}$ Hotelling dengan algoritma Fast $\mathrm{MCD}$

Gambar tersebut menunjukkan bahwa terdapat 75 nilai $T_{m c d}^{2}$ yang out of control. Untuk mencapai proses in control seperti pada Gambar 4, data yang out of control perlu dihilangkan. Dari hasil perhitungan diperoleh bahwa proses in control dapat dicapai hanya dengan 2 kali iterasi penghapusan data out of control.

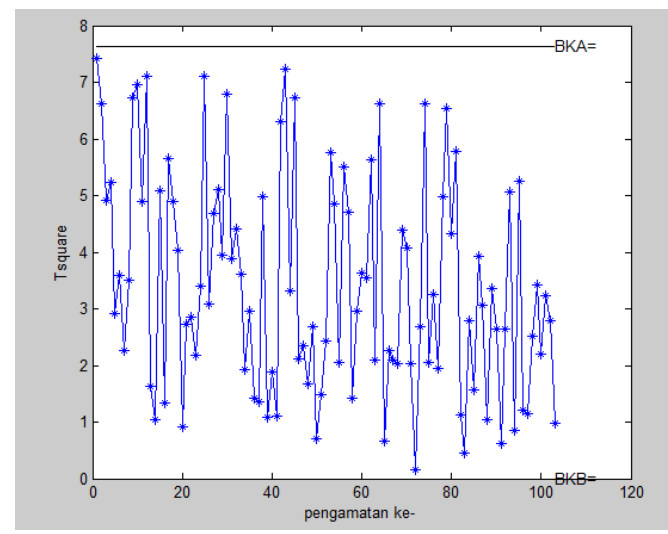


Seltuti, Erna Tri Herdiani, Nirwan Ilyas

Gambar 4. Bagan kendali $\mathrm{T}^{2}$ Hotelling dengan algoritma Fast-MCD

Perbandingan hasil perhitungan bagan kendali $\mathrm{T}^{2}$ Hotelling klasik dan bagan kendali $\mathrm{T}^{2}$ Hotelling dengan algoritma Fast MCD dapat dilihat pada Tabel 1.

Tabel 1. Perbandingan hasil perhitungan $T^{2}$ dan $T_{\text {fastMCD }}^{2}$

\begin{tabular}{|c|c|c|}
\hline \multirow{2}{*}{ Identifikasi } & \multicolumn{2}{|c|}{ Data pupuk clay putih } \\
\cline { 2 - 3 } & $T^{2}$ & $T_{\text {fast } M C D}^{2}$ \\
\hline data out of control & 14 & 75 \\
\hline Jumlah iterasi & 9 & 2 \\
\hline BPA & 7,796 & 7,796 \\
\hline
\end{tabular}

Dari Tabel tersebut dapat kita lihat bahwa data out of control lebih banyak ditemukan pada bagan kendali $\mathrm{T}^{2}$ Hotelling dengan algoritma Fast-MCD. Hal ini menunjukkan bahwa bagan kendali $\mathrm{T}^{2}$ Hotelling dengan algoritma Fast-MCD lebih efektif dalam mendeteksi pengamatan yang mengandung outlier.

\section{Indeks Kemampuan Proses}

Setelah diperoleh bagan kendali $\mathrm{T}^{2}$ Hotelling dalam keadaan pengamatan in control, maka langkah selanjutnya adalah menaksir kapabilitas proses $(C P)$ dimana sesuai dengan batas spesifikasi yang telah ditentukan oleh perusahaan. Nilai $C p$ yang diperoleh untuk bagan kendali $\mathrm{T}^{2}$ Hotelling produksi pupuk dengan bahan Clay Putih sebesar 0,1693. Sedangkan nilai $C p$ yang diperoleh untuk bagan kendali $\mathrm{T}^{2}$ Hotelling dengan algoritma Fast-MCD yaitu 0,2707 .

\section{Kesimpulan}

Perbandingan yang diperoleh adalah bagan kendali $\mathrm{T}^{2}$ Hotelling dengan algoritma Fast-MCD lebih efektif mendeteksi data yang mengandung outlier. Dari hasil perhitungan diperoleh 14 data yang out of control pada bagan kendali $\mathrm{T}^{2}$ Hotelling klasik dan 75 data yang out of control pada bagan kendali $\mathrm{T}^{2}$ Hotelling dengan algoritma Fast-MCD dengan nilai $\mathrm{BPA}=7,796$.

\section{Daftar Pustaka}

[1]. Barnett V, Lewis T., 1994. Outliers in Statistical Data. Chichester: John Wiley \& Sons, Ltd.

[2]. Bothe, Davis,R.,1997. Measuring Process Capability. McGraw-Hill Companies, United States of America.

[3]. Chenouri, S., Steiner, S. H., Variyath, A. M., 2009. A Multivariate Robust Control Chart for Individual Observations. Journal of Quality Technology, 41, (3).

[4]. Erna, 2014. Bagan Kendali $T^{2}$ Hotelling Dengan Sampel Ganda Dan Aplikasinya. Skripsi. Program Studi Matematika Fakultas Matematika dan Ilmu pengetahuan Alam. Makassar: Universitas Hasanuddin.

[5]. Hotelling, H., 1947. In Techniques of Statistical Analysis, C. Eisenhart, H. Hastay, and W. A.Wallis, eds., pp. New York, NY: McGraw-Hill.

[6]. Hubert, M dan Driessen, 2002. Fast and Robust Discriminant Analysis. Computational Statistics and Data Analysis.45.

[7]. Johnson, Richard. Dean Wichern., 2007. Applied Multivariat Statistical Analysis, 5th ed. New Jersey: Prentice Hall. 
Seltuti, Erna Tri Herdiani, Nirwan Ilyas

[8]. Montgomery, D.C.(2009). Introduction to statistical quality control (6 ${ }^{\text {th }}$ ed.) Arizona State University: John Wiley \& Sons, Inc.

[9]. Ronal, E Walpole. 2002. Probability and Statistics for Engineers and Scientist 7th. Prentice Hall, Inc: Upple Saddle River, New Jersey 017458.

[10]. Rousseeuw, P. J. (1985). Multivariate estimation with high breakdown point. In Mathematical Statistics and Applications B (W. Grossmann, G. Pflug, I. Vincze and W. Werz, eds.) 283297. Reidel, Dordrecht.

[11]. Rousseeuw, P. J., Driessen, K. 1999. A Fast Algorithm for the Minimum Covariance Determinant Estimator. Wilrijk, Belgium: Department of Mathematics and Computer Science, University of Antwerpon.

[12]. Todorov, V., \& Filzmoser, P. An Object Oriented Framework for Robust Multivariate Analysis. Vienna, Austria: United Nations Industrial Development Organization (UNIDO).

[13]. Variyath, Asokan M. dan Vattathoor, Jayasankar. 2013. Robust Control Charts for Monitoring Process Mean of Phase-I Multivariate Individual Observations. Journal of Quality and Reliability Engineering, Volume 2013, Article ID 542305. Hindawi Publishing Corporation

[14]. Walpole, R.E., Myers, R.H., Myers, S.L., \&Ye, K .(2012). Probability \& Statistics for Engineers \& Scientists (9th ed.). United States of America: Person Education Inc.

Lampiran : Identifikasi data Out Of Control dengan $\mathrm{T}^{2}$ Hotelling
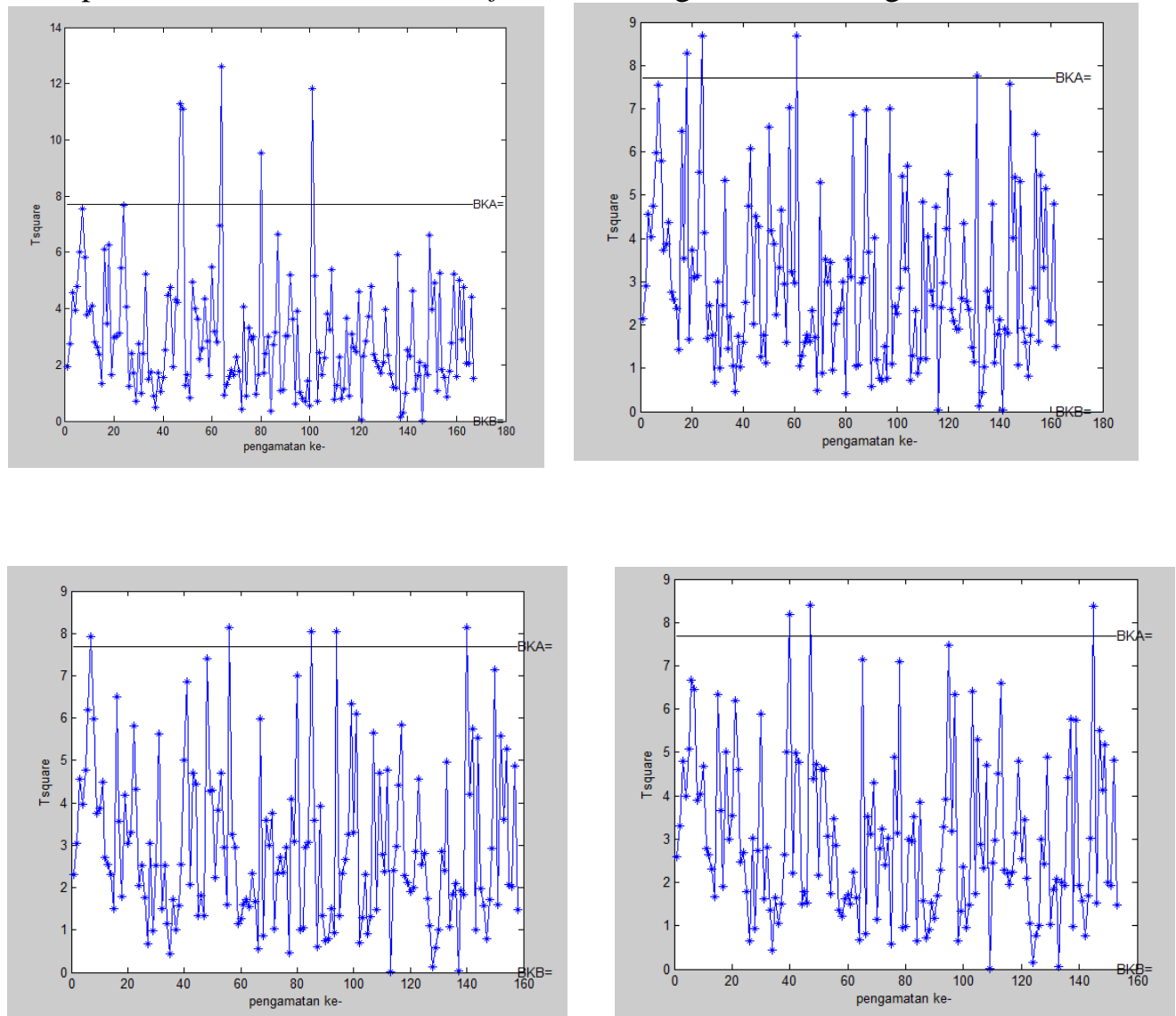

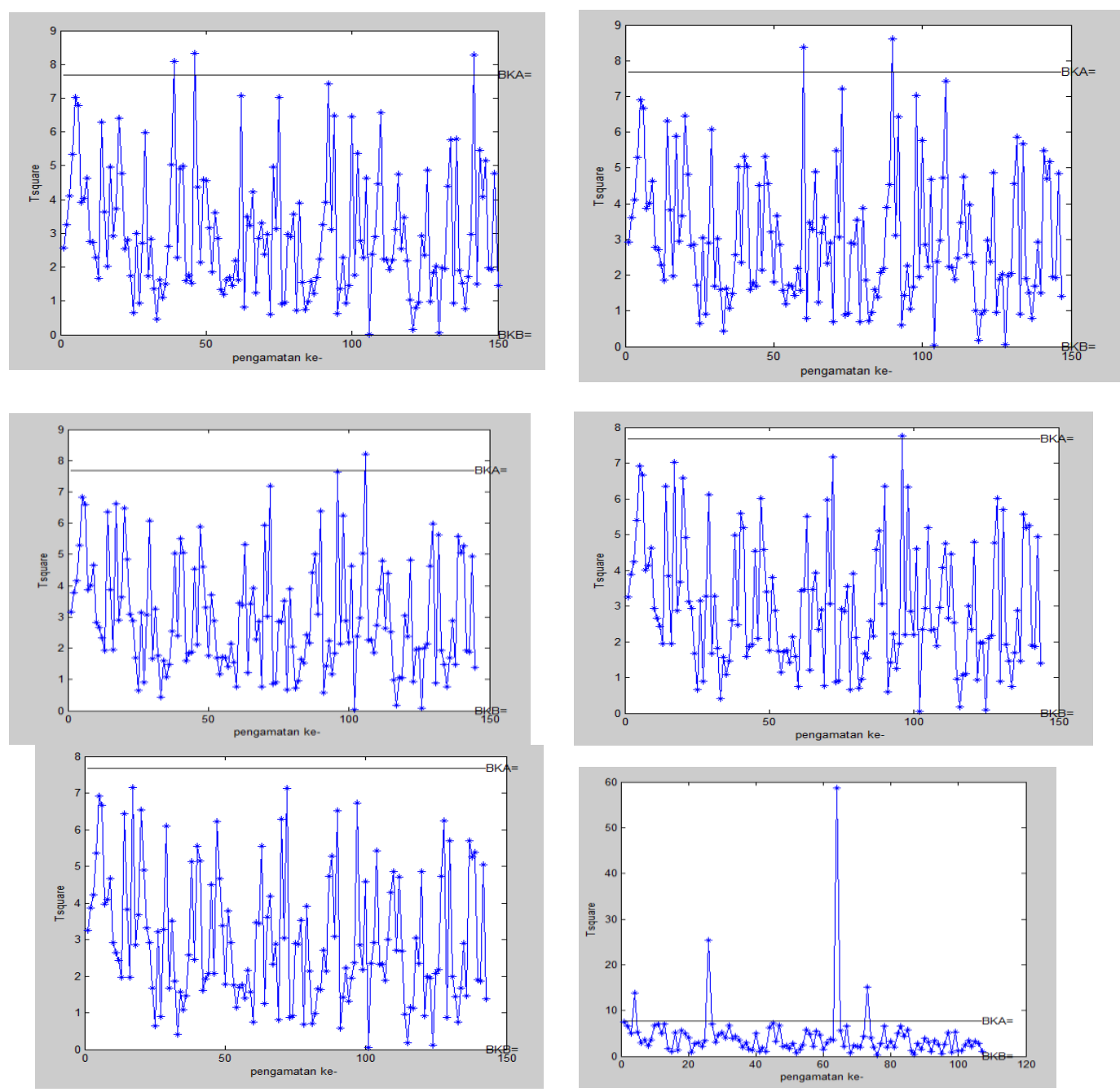

Lampiran : Identifikasi data Out Of Control $\mathrm{T}^{2}$ Hotelling dengan algoritma fast-MCD

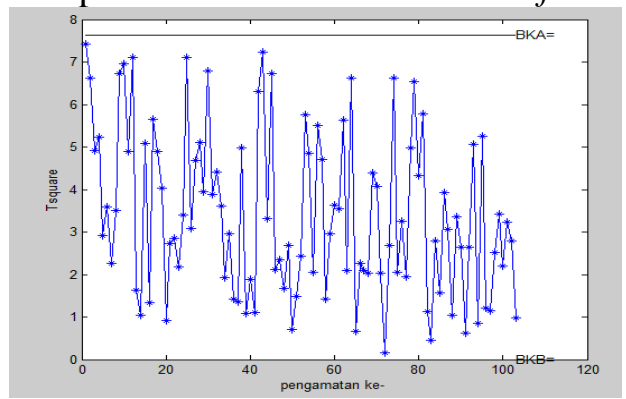

